\title{
Imbalance between the cellular proliferation and death in harderian gland of female mice with hyperprolactinemia
}

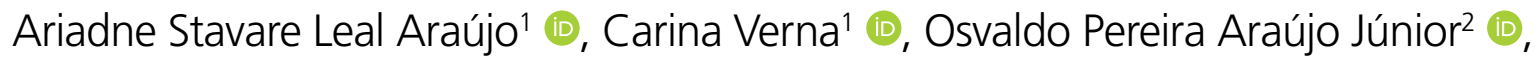 \\ José Maria Soares Júnior ${ }^{3}$ (D), Ricardo Santos Simões $^{3}{ }^{(0)}$, Edmund Chada Baracat ${ }^{3}$ (D), \\ Manuel de Jesus Simões ${ }^{1}$ (D), Regina Célia Teixeira Gomes ${ }^{1,3 *}$ (1)
}

\begin{abstract}
SUMMARY
OBJECTIVE: To assess the impact of the metoclopramide-induced hyperprolactinemia in cellular death and proliferation in the harderian gland of female mice.

METHODS: Twenty female mice were divided into two groups of 10 animals each and treated: $0.2 \mathrm{~mL}$ of saline solution (controls, Ctr) and $200 \mu \mathrm{g}$ of metoclopramide (experimental, hyperprolactinemia), both for 50 consecutive days and at 12:00 a.m. On the 50th day, the female were euthanized, and the harderian glands were removed and processed for immunohistochemistry for detected ki67 and TUNEL method. Data were statistically analyzed by unpaired Student's test $(p<0.05)$.

RESULTS: The harderian gland of the hyperprolactinemia group showed increase in the immunoexpression of Ki67 and TUNEL compared to the $C \operatorname{tr}$ group $(p<0.05)$, and there was no significant difference in the amount of porphyrin in the HPrl group compared to the Ctr group. CONCLUSION: The hyperprolactinemia led to increased cell death in the acini the harderian gland and cell proliferation in the stroma glandular, fact that suggesting a reduction process of cellular activity and fibrosis, which suggests impairment in the functioning of the lacrimal harderian.

KEYWORDS: Proliferation, cell. Harderian gland. Mice. Hyperprolactinemia.
\end{abstract}

\section{INTRODUCTION}

Hyperprolactinemia is the most common disorder of the hypothalamic-pituitary-gonadal axis ${ }^{1}$ and may have physiological causes - pregnancy, nursing, sleep, stress, sexual dysfunctions, or even a pathological cause - a tumor called prolactinoma. Hyperprolactinemia is a condition similar to hypogonadism, since it acts negatively on ovarian function ${ }^{2-5}$. However, the relationship between hyperprolactinemia and the function of the lacrimal (LG) or the harderian glands (HG) is not well defined. Prolactin (PRL) is synthesized and secreted by the adenohypophysis lactotrophs with systemic action in humans ${ }^{6}$ and rodents ${ }^{7-9}$. Understanding the endocrine changes in the glands responsible for the formation of the tear film, whether in human or animal models, is essential to understand the effects of hyperprolactinemia. The HG is a pigmented lacrimal gland found in vertebrates that have a nictitating membrane (translucent inner eyelid). The HG is in close association with the intra-orbital LG, and PRL and sex steroid hormones (estrogen

\footnotetext{
'Universidade Federal de São Paulo, Morphology and Genetics Department - São Paulo (SP), Brazil.

${ }^{2}$ Universidade Federal de São Paulo, Obstetrics and Gynecology Department - São Paulo (SP), Brazil.

${ }^{3}$ Universidade de São Paulo, Faculty of Medicine Obstetrics and Gynecology Department - São Paulo (SP), Brazil.

*Corresponding author: celiateixeira2000@yahoo.com.br

Conflicts of interest: the authors declare there is no conflicts of interest. Funding: Coordination for the Improvement of Higher Education Personnel (CAPES).

Received on August 30, 2020. Accepted on September 20, 2020
} 
and progesterone) can affect this gland, as it contains receptors for these hormones.

PRL and ovarian hormones (estrogen and progesterone) have been investigated in the animal model (female) so as to provide data for researches with metoclopramide-induced hyperprolactinemia (HPrl). Histological study showed signs of a decreased intra-orbital LG cells activity due to changes in the cell volume of the acinar cells, as well as an increased number of collagen fibers in the connective tissue that supports the LG of female mice with $\mathrm{HPr}^{5}{ }^{5,10}$. Those studies are evidence that hyperprolactinemia could lead to processes of cell death or cell proliferation, as well as tissue fibrosis in LG and HG. Tissue homeostasis is an essential physiological phenomenon that ensures a dynamic balance between cell proliferation and cell death in the maintenance and regulation of healthy tissues. Thus, an imbalance in this homeostasis can lead to a decline in the LG and HG function, which consequently contributes to eye dryness, one of the main causes of tear film instability.

This study's main goal was to analyze the cellular proliferation (Ki67) and death (TUNEL method) in the HG of female mice with metoclopramide-induced HPrl.

\section{METHODS}

The experiments were carried out at the Histology Discipline of Universidade Federal de São Paulo (UNIFESP). The protocols were designed according to the Brazilian College of Animal Experimentation. They were approved by the Institutional Ethics Committee on Animal Experimentation of UNIFESP and Review Board (Report No. 84582409/15). A total of 20 virgin female adult mice, aged 3 months old, Mus musculus, and weighing 35-40g were given food and water ad libitum at room temperature $\left(22^{\circ} \mathrm{C}\right)$ under artificial light with a $12: 12$ hour light:dark photoperiod (lights on from 7 a.m.-7 p.m.). Thereafter, they were adapted to the new environment for 2 weeks, vaginal smears were collected daily and stained by Harris-Shorr for cytological analysis for evidence of regular estrous cycles 5 . Initially, induction of HPrl was performed, 10 females received subcutaneous injections of $200 \mu \mathrm{g} /$ day of metoclopramide dissolved in $0.2 \mathrm{~mL}$ of saline solution for 50 consecutive days (hyperprolactinemic group, $\mathrm{HPrl}$ ), and 10 females received subcutaneous injections of $0.2 \mathrm{~mL}$ of saline solution for 50 consecutive days (control group, Ctr). The females were always treated at 12:00 p.m. Then, on the $50^{\text {th }}$ day, 1 hour after the last injection, a colpocytological examination of vaginal smears was performed and all animals were euthanized by excessive exposure to an association of muscle relaxant and anesthetic (xylazine $20 \mathrm{mg} / \mathrm{kg}$ plus ketamine
$100 \mathrm{mg} / \mathrm{kg}$ ), subcutaneously and, finally, HG were removed (Figure 1) and fixed for 24 hours in $10 \%$ formaldehyde in phosphate-buffered saline (PBS) for the immunohistochemistry method (IHC).

\section{Histological processing}

After fixation, tissue samples were processed in the histotechnical equipment (Lupe Ltda, Brasil), according to the classic inclusion protocol: dehydration (ethanol), diaphanization (xylol), and impregnation with liquid paraffin, in a drying oven set at $60^{\circ} \mathrm{C}$. The paraffin-embedded glands were cut into ten sections of $3 \mu \mathrm{m}$ on a Minot microtome LEICA - RM 2145 (Leica, Germany), adhered in silanized slides at $5 \%$, and dried in an oven at $37^{\circ} \mathrm{C}$ for 24 hours for detection of the cell proliferation marker (Ki67) and cell death markers (TUNEL method) on HG by immunohistochemical analyses.

\section{Immunohistochemical method}

Immunohistochemical analysis was performed for the detection of the proteins: Ki-67 cell proliferation marker (M3064, 1:200, Spring, USA), and cell death marker (TUNEL, in Situ Cell Death Detection Kit, 11684817910 Roche). The paraffin-embedded glands sections were submitted to the classic deparaffinization protocol (three xylol baths for 5 min each), rehydrated (three absolute ethanol baths for $5 \mathrm{~min}$ each, and formic acid (one bath for $3 \mathrm{~min}$ ), washed several times with running water, and then washed thrice with distilled water. Then, the sections were submitted to the IHC protocol: Fist protocol: three sections/animal were submitted to the IHC protocol for detection of Ki67: 1) antigenic recovery was performed with citrate buffer $(\mathrm{pH}$ 6.0) at $100^{\circ} \mathrm{C}$, in a steam cooker, and sections were washed with PBS ( $\mathrm{pH} 7.4$ ) thrice for 5 min each (washing procedure); 2) endogenous peroxidase was blocked with a $3 \%$ $\mathrm{H}_{2} \mathrm{O}_{2}$ solution at 10 vol./methanol (1:1) for 25 min (washing procedure); 3) non-specific sites were blocked and the cell membrane was permeabilized with $0.5 \%$ Tween $+1 \%$ bovine serum albumin (BSA)/PBS ( $\mathrm{pH} 7.4)$ (washing procedure); 4) sections were incubated with primary antibody diluted in PBS ( $\mathrm{pH} 7.4) / 1 \%$ BSA for 18 hours in a humidity chamber at $4^{\circ} \mathrm{C}$ (washing procedure); 5) next, the sections were incubated with the post primary VECTASTAIN ${ }^{\circledast}$ Elite $\mathrm{ABC}$ anti-rabbit kits (PK-6101, Vector Laboratories, USA) (incubated with anti-rabbit $\operatorname{IgG}$ for $30 \mathrm{~min}$ at $37^{\circ} \mathrm{C}$, and the same washing process), and again incubated with the avidi/ biotin complex for $30 \mathrm{~min}$ at $37^{\circ} \mathrm{C}$ (plus washing process); 6) incubated with the chromogen, diaminobenzidine chromogen (DAB) (DAKO Cytomation, Denmark) for $3 \mathrm{~min}$ 
(washing process); 7) counterstained with hematoxylin for two minutes, and the sections were washed several times with running water. Finally, the sections were submitted to the classic resin mounting protocol: all sections were immersed in three absolute ethanol baths for five minutes each, after three xylol baths for five minutes each, and then, the slides were covered using Entellan ${ }^{\circledR}$ (Merck, Germany) resin and cover slip. These methods consist of brown-brown staining in the nucleus. Negative controls were obtained by replacing the primary antibody with the respective concentration of non-immune IgG from a different species, Figure 2.

Second protocol: three sections/animal were submitted to the IHC protocol for detection of cell death by the TdT-mediated dUTP-biotin Nick End Labeling ( TUNELIn Situ Cell Death Detection Kit, Roche Diagnostics, 11684795910), carried out according to the manufacturer's instructions:

1) antigenic recovery: sections were subjected to enzymatic antigenic recovery with $20 \mu \mathrm{g} / \mathrm{mL}$ Proteinase $\mathrm{K}$ in 10 mM Tris-HCl, pH 7.6 (Gibco, Grand Island, NY, USA), for $20 \mathrm{~min}$ at $37^{\circ} \mathrm{C}$, and washing procedure; 2) blocking of endogenous peroxidase with a $3 \% \mathrm{H}_{2} \mathrm{O}_{2}$ solution at 10 vol./methanol (1:1) for 25 min (washing procedure); 3) the sections were incubated with bromodeoxyuridine (BrdU), conjugated biotinylated nucleotides (TdTs), together with biotin/streptavidin conjugated rabbit anti-BrdU antibody, and then covered with parafilm for $60 \mathrm{~min}$ at $37^{\circ} \mathrm{C}$, protected from light with aluminum foil, and washing procedure; 4) the sections were incubated with the antidigoxygenin peroxidase conjugate (DPC) and then covered with parafilm for $30 \mathrm{~min}$ at $37^{\circ} \mathrm{C}$, plus washing procedure. Next, the incubation with the chromogen, the counterstaining, and the same assembly and immunostaining procedures were performed as explained above. In both methods, brown-brown staining in the nucleus associated with the histological characteristics of the cells was observed in the nucleus, in the cytoplasm or in the region bordering the cell membrane. Negative controls were obtained by replacing the primary antibody with the respective concentration of non-immune IgG from a different species, Figure 2.

\section{Semiquantification}

In this method, the presence of the brown-brown staining corresponds to a positive antigen-antibody-DAB reaction. Photomicrographs of the immunostaining sections were digitalized using a computerized system; sections were scanned

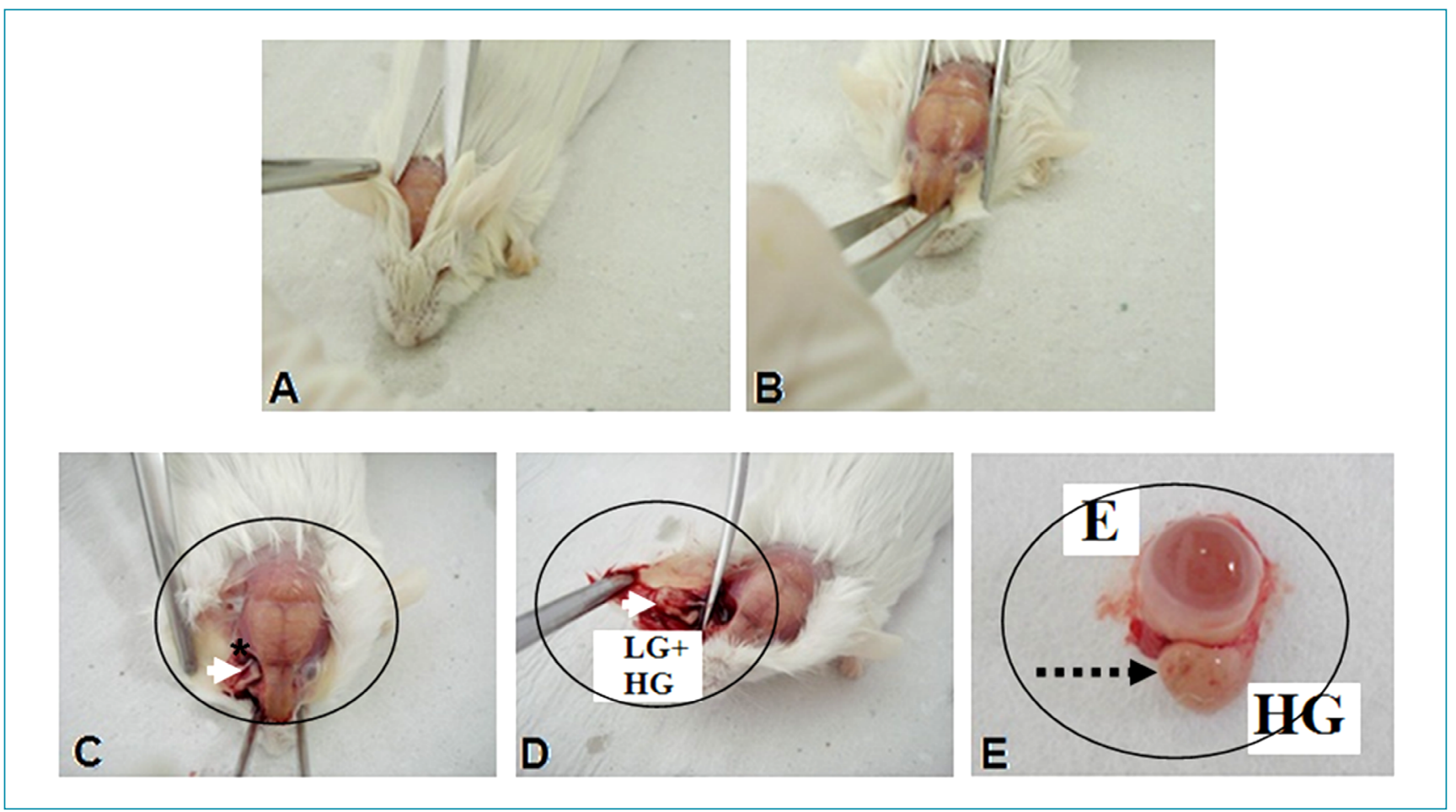

Figure 1. Procedure for the removal of intra-orbital harderian gland (HG). Before surgery, female mice were euthanized by deepening anesthetic and relaxing the muscle. Then, an incision was made in the skin (A and B), and the optic nerve $\left(^{*}\right)$, eyes (E), and lacrimal and harderian glands (white arrowhead) were exposed ( $D$ and $E)$. Then, ophthalmic forceps was used to extract the lacrimal (LG) and harderian glands (HG) together (C and D) and then carefully separated (black arrow) (D). 
with a Histech 3D scanner (Budapest, Hungary) and visualized by the Pannoramic Viewer software. Ten fields (areas in $\mu \mathrm{m}^{2}$ with magnification from 100x to 400x) were selected in order to cover the entire length of the section, allowing for complete analyses of each gland. The Image Pro Plus7 software carried out an analysis (software of Media Cybernetics, USA) with a magnification from 100x to 400x. Results are expressed as \% marked area/total area in $\mu \mathrm{m}^{2}$. Analyses of the IHC photomicrographs were conducted by two blinded histologists.

\section{Statistical Analysis}

Measurements were submitted to the Student's $t$ test to determine the differences between the groups studied. Data are presented as mean \pm SD. All statistical tests were performed using GraphPad Prism software, version 7.0 for Windows (GraphPad Software). The significance level was set at $\mathrm{p}<0.05$. All data were expressed as mean \pm SD.

\section{RESULTS}

Morphological description and results of porphyrin quantification are summarized in Figure 2. The increased amount of porphyrin is not significant in the HPrl group compared to the Ctr one.

\section{Semiquantification of the Immunohistochemistry}

The results of the semiquantification of immunoexpression are summarized in Figure 2.

- the increase in the immunoexpression of the cell proliferation marker (Ki67) was significant in the HPrl group compared to the Ctr group: $(\mathrm{p}<0.05)$.

- the increase in the immunoexpression of the cell death marker by DNA fragmentation (TUNEL) was significant in the HPrl group compared to the Ctr group: $(\mathrm{p}<0.05)$.

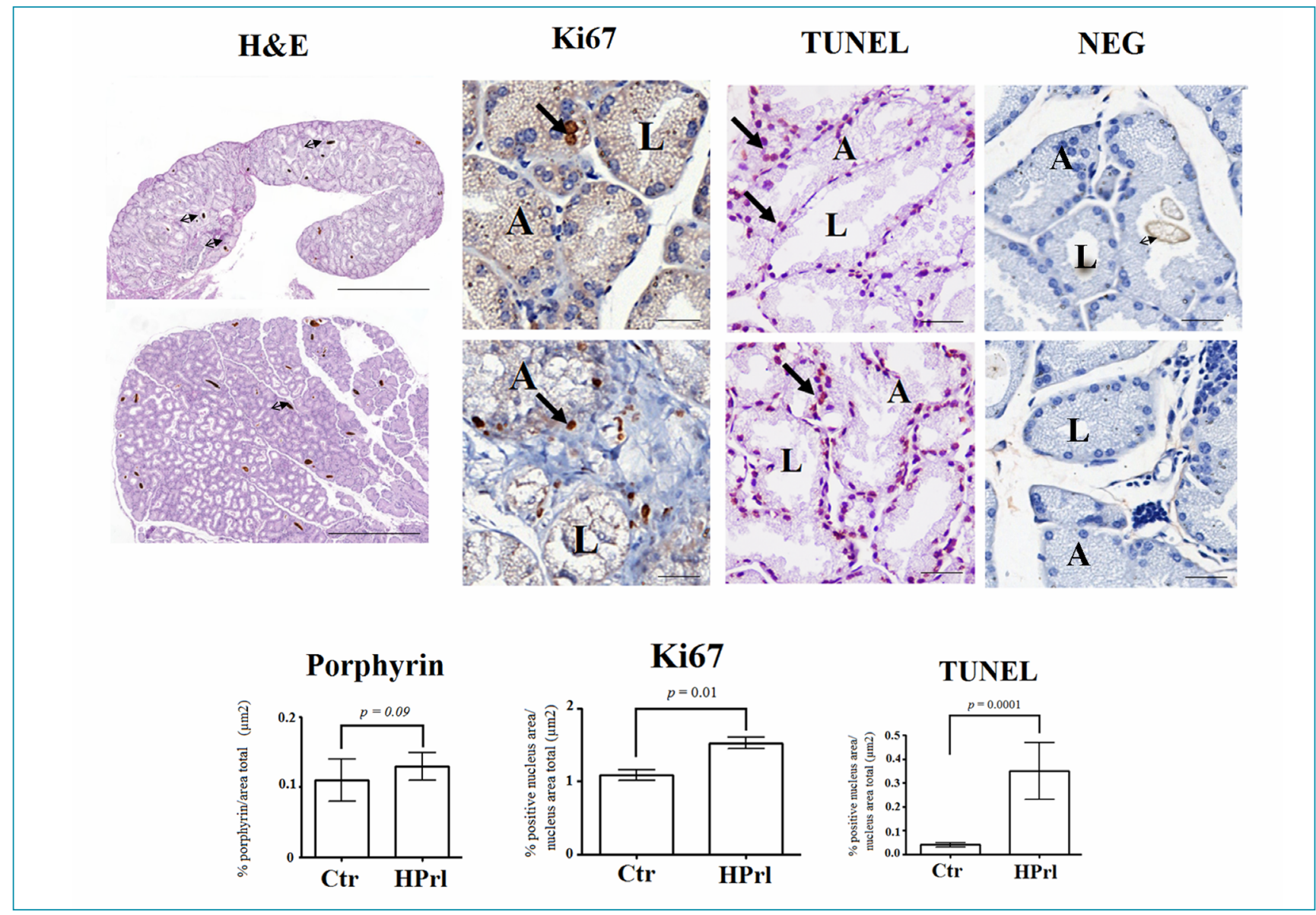

Figure 2. Representative photomicrographs of immunohistochemistry in the harderian gland of female mice of the control group and group with hyperprolactinemia. Note that the presence of brown nuclear reactivity identified ki67 and TUNEL positive cells. Additionally, it was observed in hematoxylin and eosin histology and porphyrin pigments in brownish-brown in the lumen of some acini. Therefore, the negative control (negative) was included in the figure. Observations were made in $\mathrm{X} 100$ and $400 \mathrm{x}$ magnification (Bar=50 $\mu \mathrm{m}$ ). The graphs represent the results expressed as mean \pm standard deviation, number of animals $(n=10)$. *Significant values, and statistical test: Student's t unpaired. 


\section{DISCUSSION}

The present study's results show that hyperprolactinemia altered the proliferation and cell death of HG acini. It also indicates that morphological changes such as cellular disorganization, alteration in the volume of acinar cells, and the spacing between acini were similar to those found in LG. These cellular changes may be due to the direct effect of prolactin on LG and HG through prolactin receptors, or due to an imbalance in ovarian hormones.

Our morphological data on the action of HPrl in HG were similar to those found by Verna et al. ${ }^{11}$ in intra-orbital LG (non-pregnant and pregnant). The same animal model was used for HPrl. The authors suggested that these results would indicate signs of decreased cellular activity. Our data show an increase in the TUNEL immunoexpression, a fact that results in higher death of acinar cells in the HG of females with HPrl.

Araujo et al. ${ }^{5}$, in agreement with previous studies that used the same HPrl model ${ }^{10,11}$, showed that serum PRL levels increased and that serum progesterone and estrogen levels decreased in all animals with $\mathrm{HPrl}$ when compared to control ones. Those findings suggest an impairment in LG function caused by increased serum PRL levels and decreased estrogen and progesterone. The primary condition related to the imbalance of sex hormones (estrogen/androgen) and PRL is Sjogren's syndrome, also known as dry eye syndrome. Carriers of the Sjogren's syndrome have high pro-inflammatory cytokines in the tear film and in the epithelium of the ocular surface ${ }^{12,13}$. Our data show an increase in Ki67 immunoexpression, which results in a higher proliferation of the acinar cells of HG and fibroblasts in the connective tissue around the acini of females with HPrl.

In humans, the LG is formed by an orbital portion, an eyelid portion (serous glands), and the meibomian glands (specialized sebaceous glands) that produce the oily components (meibum) of the outer lipid layer. Those components are responsible for preventing the overflow and evaporation of the tear. However, in murine, there is a third type of eye gland in the orbinal portion (intra-orbinal), the harderian glands (some authors consider HG to be a type of LG while others believe it to be an accessory gland in the LG). HG are found on vertebrates that have a nictitating membrane (translucent inner eyelid) $)^{4-6,14}$.

Interestingly, the epithelial-derived HG consists of 2 types of secretory cells. The more numerous ones, type A cells, are responsible for the secretion of lipid droplets, while type B cells produce dark granules of multilamellar bodies (porphyrin pigments) 5 .

Antolín et al. (1996) ${ }^{17}$ show that HG of male hamsters present a very low rate of damaged cells that progressively increases after castration. This rise runs parallel to that of porphyrin synthesis and deposits, decreased Type B secretory cells, and finally concluded that this event is not a physiological cell death (apoptosis) but the consequence of the toxic accumulation of porphyrins (necrosis). Our data showed increased porphyrin in the HG of animals with HPrl, although not significant, leading us to believe in a relationship between cell death and increased porphyrin. Future studies are needed.

Most of the cells that make up the acini of the HG die from autophagy due to the secretion release mechanism, consisted of exocrine and holocrine glands. Thus, even though they may die from apoptosis ${ }^{16}$, it is common to visualize remains of dead cells in the secretion product. Cells have developed biological mechanisms to control abnormal cell growth and maintain metabolic homeostasis. One of the known mechanisms is cell death due to autophagy or apoptosis ${ }^{15,17}$. Our results suggest that baseline levels of cell death, whether due to apoptosis or autophagy, are necessary to maintain the homeostasis of the HG. Histopathological studies of healthy subjects showed that, with aging, processes such as periductal and interacinar fibrosis and, ultimately, acinar atrophy are associated with the primary deficiency of the LG, leading to dry eye ${ }^{18}$.

In summary, the data from this study showed that the hyperprolactinemic state could lead to an imbalance between cell death and proliferation, which can impair the functioning of the hardenian gland.

\section{CONCLUSION}

HPrl led to increased cell death in the acini the HG and cell proliferation in the stroma glandular, fact that suggesting a reduction process of cellular activity and fibrosis, which suggests impairment in the functioning of the lacrimal harderian.

\section{AUTHORS" CONTRIBUTIONS}

ASLA: Conceptualization, Data Curation, Formal Analysis, Writing - Original Draft, Writing - Review \& Editing. CV: Conceptualization, Data Curation, Formal Analysis. OPAJ: Writing - Original Draft, Writing - Review \& Editing. JMSJ: Formal Analysis. RSS: Writing - Original Draft, Writing - Review \& Editing. ECB: Writing - Original Draft, Writing - Review \& Editing. MJS: Conceptualization, Data Curation, Formal Analysis. RCTG: Conceptualization, Data Curation, Formal Analysis, Writing - Original Draft, Writing - Review \& Editing. 


\section{REFERENCES}

1. Gomes RC, Maioral GC, Verna C, Patriarca MT, Nader HB, Simões RS, et al. Hyperprolactinemia changes the sulfated glycosaminoglycan amount on the murine uterus during the estrous cycle. Fertil Steril. 2013;100(5):1419-27. https://doi. org/10.1016/j.fertnstert.2013.06.048

2. Panzan MQ, Júnior JM, da Motta EL, Haapalainen EF, de Jesus Simões M, Baptista HA, et al. Metoclopramide-induced hyperprolactinaemia caused marked decline in pinopodes and pregnancy rates in mice. Hum Reprod. 2006;21(10):2514-20. https://doi.org/10.1093/humrep/del093

3. Rossi AG, Teixeira Gomes RC, de Jesus Simões $M$, Dos Santos Simões R, Oliveira PB, Soares JM Jr, et.al. Effects of metoclopramide-induced hyperprolactinemia on the prolactin receptor of murine endometrium. Fertil Steril. 2010;93(5):1643-9. https://doi.org/10.1016/j.fertnstert.2009.02.021

4. Messmer EM. The pathophysiology, diagnosis, and treatment of dry eye disease. Dtsch Arztebl Int. 2015 Jan 30;112(5):7181; quiz 82. https://doi.org/10.3238/arztebl.2015.0071

5. Araujo ASL, Simões MJ, Verna C, Simões RS, Soares Junior JM, Gomes Rct. Influence of hyperprolactinemia on collagen fibers in the lacrimal gland of female mice. Clinics. 2015;70(9):632-7. https://doi.org/10.6061/clinics/2015(09)07

6. Molitch ME. Endocrinology in pregnancy: management of the pregnant patient with a prolactinoma. Eur J Endocrinol. 2015;172(5):R205-13. https://doi.org/10.1530/EJE-14-0848

7. Wang $Y$, Chiu $C T$, Nakamura T, Walker AM, Petridou B, Trousdale MD, et al. Elevated prolactin redirects secretory vesicle traffic in rabbit lacrimal acinar cells. Am J Physiol Endocrinol Metab. 2007;292(4):E1122-34. https://doi.org/10.1152/ ajpendo.00381.2006

8. Wood RL, Zhang J, Huang ZM, Gierow JP, Schechter JE, Mircheff AK, et al. Prolactin and prolactin receptors in the lacrimal gland. Exp Eye Res. 1999;69(2):213-26. https://doi. org/10.1006/exer.1999.0690

9. Teixeira Gomes RC, Verna C, Nader HB, dos Santos Simões R, Dreyfuss JL, Martins JR, et al. Concentration and distribution of hyaluronic acid in mouse uterus throughout the estrous cycle. Fertil Steril. 2009;92(2):785-92. https://doi.org/10.1016/j. fertnstert.2008.07.005
10. Verna C, Júnior Soares JM, Martins FW, Teixeira RC, Mosquette R, Simões RS, et al. Effects of metoclopramideinduced hyperprolactinemia on the murine corneal. Arq Bras Oftalmol. 2006;69(5):645-9. https://doi.org/10.1590/s000427492006000500004

11. Verna C, Martins FW, Mosquette R, Simões RS, Simões MJ, Soares Júnior JM, et al. Effects of metoclopramide-induced hyperprolactinemia on the lacrimal gland: experimental study. Rev Bras Ginecol Obstet [online]. 2005;27(9):524-8 https:// doi.org/10.1590/S0100-72032005000900004

12. Walcott $B$. The lacrimal gland and its veil of tears. News Physiol Sci. 1998;13(2):97-103. https://doi.org/10.1152/ physiologyonline.1998.13.2.97

13. Nandoskar $P$, Wang $Y$, Wei R, Liu Y, Zhao $P$, Lu M, et al. Changes of chloride channels in the lacrimal glands of a rabbit mode of Sjögren syndrome. Cornea. 2012;31(3):273-9. https://doi. org/10.1097//CO.0b013e3182254b42

14. Lütjen-Drecoll E, Schenholm M, Tamm E, Tengblad A. Visualization of hyaluronic acid in the anterior segment of rabbit and monkey eyes. Exp Eye Res. 1990;51(1):55-63. https://doi.org/10.1016/0014-4835(90)90170-y

15. Koenig $U$, Fobker $M$, Lengauer $B$, Brandstetter $M$, Resch GP, Gröger $M$, et al. Autophagy facilitates secretion and protects against degeneration of the Harderian gland. Autophagy. 2015;11(2):298-313. https://doi.org/10.4161/15548627.20 14.978221

16. Shalini S, Dorstyn L, Dawar S, Kumar S. Old, new and emerging functions of caspases. Cell Death Differ. 2015;22(4):526-39. https://doi.org/10.1038/cdd.2014.216

17. Antolín I, Rodríguez C, Uría H, Sáinz RM, Mayo JC, Kotler ML, et al. Castration increases cell damage induced by porphyrins in the Harderian gland of male Syrian hamster. Necrosis and not apoptosis mediates the subsequent cell death. J Struct Biol. 1996;116(3):377-89. https://doi.org/10.1006/jsbi.1996.0055

18. Ogawa Y, Razzaque MS, Kameyama K, Hasegawa G, Shimmura $\mathrm{S}$, Kawai $\mathrm{M}$, et al. Role of heat shock protein 47, a collagenbinding chaperone, in lacrimal gland pathology in patients with cGVHD. Invest Ophthalmol Vis Sci. 2007;48(3):1079-86. https://doi.org/10.1167/iovs.06-0601 